\title{
TERRORISMO E EMPREENDEDORISMO: A SEGURANÇA PÚBLICA COMO JUSTIFICATIVA DO LIBERALISMO ECONÔMICO
}

\author{
Ana Clara Carvalho Caldeira
}

Universidade do Oeste Paulista - UNOESTE, curso de Direito, Presidente Prudente, SP. E-mail: carvalhocaldeiraaninha@hotmail.com

\begin{abstract}
RESUMO
Este trabalho trata de um assunto cuja importância é definitiva para o desenvolvimento e economia de um Estado. A metodologia constou de diversos autores, professores, doutrinadores e especialistas que estudaram o assunto. Os resultados obtidos foram satisfatórios e convincentes, visto que, a maioria dos especialistas descrevia de forma clara e com precisão assuntos relacionados aos crimes realizados por grupos armados e sua definição. Concluindo que, ataques terroristas consequentemente têm aumentado, causando inúmeras mortes, infligindo bens jurídicos individuais e coletivos, acarretando sérios problemas econômicos e retirando a ordem e soberania de diversos territórios. Como um país emergente, em pleno desenvolvimento, mesmo com a crise, o Brasil chama a atenção. O objetivo deste estudo foi mostrar ao leitor a sua definição diante da análise constitucional e penal, a importância deste instituto na atualidade, a atual política de guerra e a desestruturação que esse pode afetar na economia e desenvolvimento de um país.
\end{abstract}

Palavras-chave: Terrorismo, Bem Jurídico-penal, Política Criminal.

\section{TERRORISM AND ENTREPRENEURSHIP: PUBLIC SECURITY AS JUSTIFICATION OF ECONOMIC LIBERALISM}

\section{ABSTRACT}

This work dealt with a subject whose importance is definitive for the development and economy of a State. The methodology consisted of several authors, teachers, lecturers and specialists who studied the subject. The results were satisfactory and convincing, since most experts clearly and accurately described issues related to crimes committed by armed groups and their definition. It is concluded that terrorist attacks have consequently increased, causing countless deaths, inflicting individual and collective legal property, causing serious economic problems and removing the order and sovereignty of various territories. As an emerging country, in full development, even with the crisis, Brazil draws attention. The purpose of this study was to show the reader the definition of constitutional and penal analysis, the importance of this institute today, the current war policy and the disruption that it can affect in the economy and development of a country.

Keywords: Terrorism, Criminal juridical property, Criminal policy

\section{INTRODUÇÃO}

Com os grandes avanços da tecnologia, bem como o desenvolvimento da humanidade, a criminalidade também muda, desenvolve-se e infelizmente aumenta, o direito penal deve então, acompanhar essas mudanças na sociedade (de fato, não só o direito penal como todos os ramos do direito), conforme a criminalidade muda ele também se modifica. Após as duas Grandes Guerras, observou-se que o terrorismo veio como uma forma de recurso político, porém após o terrível ataque pelo grupo liderado por Osama Bin Laden em 11 de setembro, literalmente houve 
uma bomba de terror, assumindo maiores dimensões, pois trouxe aumento dos ataques. Os atos praticados por integrantes de grupos armados geram grande dano social, político e econômico. Há dúvida quanto a segurança da sociedade, o que causa grande medo para esta. Este tema têm se tornado cada vez mais recorrente na atualidade, bem como a política de guerra criada no governo de G. Bush liderada pelos EUA, onde há autores, como Tzvetan Todorov (o remédio é pior que a enfermidade) que afirmam que esta medida é errada, e, ao invés de controlar, acaba por influenciar a prática do terrorismo.

O objetivo deste trabalho foi mostrar ao leitor a definição trazida pela nossa mais recente lei no 13.260/16, em seu âmbito constitucional e penal, mostrando a grande importância desse fato para o século XXI. Os danos à economia e empreendedorismo que pode causar, baseando-se em diversos autores, como Luiz Regis Prado (princípio da exclusiva proteção do bem jurídico do direito penal) e fatos ocorridos nos dias atuais de ataques em vários países do mundo.

\section{METODOLOGIA}

A metodologia deste trabalho constou da leitura da própria lei antiterrorismo (LEI № 13.260/2016), bem como seu tratamento no Título II, Capítulo I, da Carta Magna Brasileira, constou da análise de diversas obras doutrinárias e fatos ocorridos atualmente.

No Brasil, a normatização específica da atuação de grupos armados é recente, utilizando o método indutivo, com pesquisas e leitura de artigos já publicados que tratam dessa problemática que vêm sendo cada vez mais frequente em todo o mundo, milhares de estudiosos demonstraram o quanto é importante destacar o tema pois o terrorismo é um fato, e é presente no dia-a-dia de milhares de pessoas, há sofrimento, imposição, tortura e invasão.

\section{RESULTADOS}

Existe uma grande preocupação com os ataques terroristas, diante das diversas leituras o ponto em comum foi que todos os autores afirmaram que houve um aumento dos ataques, e cada vez mais surgem novas ocorrências. André Luís Callegari e Raul Marques Linhares ressaltam que o momento atual é caracterizado por grandes avanços tecnológicos, que aproximaram os distantes, surgindo também novas necessidades de segurança à população, pois há a sensação de impotência e medo ao redor de todo o mundo, que aumenta cada vez mais por também aumentar o número de ataques (CALLEGARI, A. L.; LINHARES, R. M, 2014, p. 125-132). Por este fato o assunto é extremamente importante, com a sociedade atual, a situação deveria ser diferente, levando os direitos humanos no ápice, evitando conflitos e guerra entre os países. Os resultados foram satisfatórios pois os doutrinadores e estudiosos forneciam raciocínios suficientes para a compreensão do tema.

\section{DISCUSSÃO}

\section{O TERRORISMO E A CONSTITUIÇÃO FEDERAL}

A Constituição Federal repudiou o delito de terrorismo, sem qualquer exceção, em que seus integrantes são preparados para a transmissão de mensagens ideológicas através da aplicação da violência. O nosso ordenamento jurídico, não permite condutas que atentem contra a Federação e o Estado Democrático de Direito, garantindo aos indivíduos a defesa da paz; solução pacífica dos conflitos e o repúdio ao terrorismo e ao racismo conforme o art. 4o da CF/88 "Art. 4응 A República Federativa do Brasil rege-se nas suas relações internacionais pelos seguintes princípios: [...] VIII - repúdio ao terrorismo e ao racismo".

O tratamento a essas organizações, na CF/88, é elencado expressamente em seu Título II Dos Direitos e Garantias Fundamentais; Capítulo I; Dos Deveres e Garantias Individuais e Coletivos, art.5ㅇ, incisos XLIII e XLIV reforçando o repúdio a esse fenômeno, explicitando que, além de se 
tratar de crime inafiançável, insuscetível de graça e anistia, também é imprescritível. Ou seja, o crime de ação de grupos armados não se sujeita as regras prescricionais do Código Penal e através dessa repressão e prevenção ao terrorismo, a constituição visa proteger não somente os cidadãos brasileiros, mas todo o território (soberania nacional art. 1ㅇ, inciso I, CF/88) abrangendo seus recursos, nossa cultura e liberdade de escolha (pluralismo político art. 10, inciso V, CF/88) advinda da Democracia em que o cidadão é livre para votar e eleger os seus representantes.

\section{A DEFINIÇÃO LEGAL DO TERRORISMO NO BRASIL ( ART. 2 DA LEI №13.260/2016)}

O Terrorismo é o ato de imposição da vontade através do terror, ou seja, através do medo e do pânico. Trata-se de um método tanto psicológico como físico. $O$ art.2ํ da lei 13.260/16 trás o seu conceito, de acordo com a novatio legis:

Art. $2^{\circ} \mathrm{O}$ terrorismo consiste na prática por um ou mais indivíduos dos atos previstos neste artigo, por razões de xenofobia, discriminação ou preconceito de raça, cor, etnia e religião, quando cometidos com a finalidade de provocar terror social ou generalizado, expondo a perigo pessoa, patrimônio, a paz pública ou a incolumidade pública.

Aqui, o legislador é claro explicitando que o terrorismo não ocorre apenas por razões de religião como a grande maioria das pessoas o reconhece por ser mais frequente a intolerância à religiões diversas, mas também por razões de xenofobia, discriminação ou preconceito, em que seus agentes não aceitam a diversidade de culturas ou características hereditárias como a cor e etnia, ou seja, não aceitam aqueles que são diferentes de sua própria identidade como um todo, bem como o xenofobismo; onde uma pessoa de nacionalidade diferente não é aceita pelos indivíduos do meio em que se encontra, por essas razões, os sujeitos ativos comandados por seus líderes através do "terror social ou generalizado" querem impor suas determinações de identidade, religião e pensamento ou até mesmo suas ideologias políticas.

Além disso, a Lei Antiterrorismo após classificar e conceituar o ato, o diferencia das manifestações políticas feitas para reivindicação de direitos difusos e coletivos:

Art. $2 .^{\circ}[\ldots] \S 2^{\circ} \mathrm{O}$ disposto neste artigo não se aplica à conduta individual ou coletiva de pessoas em manifestações políticas, movimentos sociais, sindicais, religiosos, de classe ou de categoria profissional, direcionados por propósitos sociais ou reivindicatórios, visando a contestar, criticar, protestar ou apoiar, com o objetivo de defender direitos, garantias e liberdades constitucionais, sem prejuízo da tipificação penal contida em lei.

O terrorismo conforme a lei passa a ser punido com penas de 15 a 30 anos de reclusão que devem ser cumpridas inicialmente em regime fechado. Dispõe ela casos diversos, com penas diversas, dependendo se há consumação com a morte da vítima ou lesão corporal. A lei, parte do conceito de que o terrorismo é um delito de imposição de homogeneidade à suas crenças, doutrinas ou modo de regência do próprio governo e Estado, trata-se de voltar-se contra o Estado por assuntos principalmente políticos, querer retirar o direito que é de uma coletividade, determinando o que se deve ou não ser redigido. Seus agentes para chegarem a seu objetivo, decidem cometer atos ilícitos, utilizando de violência e imposição, através de meios e instrumentos cruéis, que podem ser letais a qualquer indivíduo, como as bombas explosivas.

Art. $2^{\circ}[\ldots] \S 1^{\circ}$ São atos de terrorismo: I - usar ou ameaçar usar, transportar, guardar, portar ou trazer consigo explosivos, gases tóxicos, venenos, conteúdos biológicos, químicos, nucleares ou outros meios capazes de causar danos ou promover destruição em massa; II - (VETADO); 
III - (VETADO); IV - sabotar o funcionamento ou apoderar-se, com violência, grave ameaça a pessoa ou servindo-se de mecanismos cibernéticos, do controle total ou parcial, ainda que de modo temporário, de meio de comunicação ou de transporte, de portos, aeroportos, estações ferroviárias ou rodoviárias, hospitais, casas de saúde, escolas, estádios esportivos, instalações públicas ou locais onde funcionem serviços públicos essenciais, instalações de geração ou transmissão de energia, instalações militares, instalações de exploração, refino e processamento de petróleo e gás e instituições bancárias e sua rede de atendimento; $\mathrm{V}$ - atentar contra a vida ou a integridade física de pessoa: Pena - reclusão, de doze a trinta anos, além das sanções correspondentes à ameaça ou à violência. $\S 2^{\circ} 0$ disposto neste artigo não se aplica à conduta individual ou coletiva de pessoas em manifestações políticas, movimentos sociais, sindicais, religiosos, de classe ou de categoria profissional, direcionados por propósitos sociais ou reivindicatórios, visando a contestar, criticar, protestar ou apoiar, com o objetivo de defender direitos, garantias e liberdades constitucionais, sem prejuízo da tipificação penal contida em lei.

\section{O TERRORISMO E O PRINCIPIO DA EXCLUSIVA PROTEÇÃO DO BEM JURÍDICO}

O principio da exclusiva proteção do bem jurídico que coloca limites ao direito penal, é o princípio que veda a punição de atos que não atinjam o bem jurídico tutelado, ou seja, atos meramente internos, da vontade interior do agente, desse modo, para que haja a efetiva punição do Estado a um indivíduo, pelo princípio da exclusiva proteção do bem jurídico, é necessário que ele pratique um ato definido como crime ou contravenção penal e que esse ato exteriorizado pelo sujeito ativo venha a atingir aquele bem cuja lei protege, concluí-se que, o direito só deve intervir quando o bem jurídico tutelado for lesionado ou colocado a perigo de lesão. Segundo Luiz Regis Prado

O pensamento jurídico moderno reconhece que o escopo imediato e primordial do Direito Penal reside na proteção de bens jurídicos essenciais ao indivíduo e à comunidade -, dentro do quadro axiológico constitucional ou decorrente da concepção de Estado de Direito democrático (teoria constitucional ampla ou intermediária) [...] (PRADO, 2007, v.1, p.140).

Cabe então, a Constituição definir o bem jurídico que o direito penal deve proteger, sendo esse princípio ligado à própria função do direito penal, qual seja, a proteção desse bem jurídico definido na Constituição. Bem ou mal, e a pretexto de garantir a segurança nacional, define-se o delito de terrorismo com intuito de tutelar a vida, a liberdade individual e coletiva, a incolumidade pública, a paz social e a ordem pública, ante os possíveis atentados terroristas.

Afinal, o Direito Penal só pode e deve atuar dentro de seus limites assim considerados na própria lei penal, punindo aquele que lesionar, ou expor a perigo de lesão o determinado bem jurídico tutelado, ou seja, impondo uma sanção ao agente que infrinja seu preceito primário e cause dano ao exclusivo bem que esteja sob a proteção do direito penal. Para a efetiva punição, o ato deve ser exteriorizado.

\section{EFEITOS AS NOVAS PROFISSÕES EMPREGO E EMPREENDEDORISMO}

Uma das grandes consequências do terrorismo é a "Guerra", que desestrutura um país por completo. O terrorismo, além de tudo, é um ato de pânico universal por causar medo e assustar as 
pessoas do mundo todo. Como será a educação das crianças e jovens que crescem com a revolta, preconceito e violência ao seu redor? Obviamente, se tornarão parte desses grupos, pois desde muito cedo são preparados para tirarem a liberdade de uma sociedade inteira, são dominados por ideologias através de seus líderes, um homem-bomba é absolutamente formado para essa tarefa. Organizações de grupos terroristas, são financiadas através de atos ilícitos e ilegais, como o Estado Islâmico que através de sequestros, roubos, extorsões e cobranças exorbitantes de impostos destroem e acabam com o governo de um país.

O Brasil, sendo um país rico em recursos naturais, com grandes pontos turísticos, rico em petróleo, sal mineral, área territorial extensa (o maior país da América Latina), com um contingente populacional jovem, maiores produtores de carne, soja, café e outros commodities chama a atenção ao redor do mundo, devendo se atentar aos grupos armados, pois além desses recursos que geram grandes lucros, os jovens são aqueles mais fáceis de serem persuadidos.

Os ataques de grupos terroristas causam grandes impactos econômicos, principalmente para o turismo, onde alguns países dependem desse tipo de atividade; a exemplo da França que possuí parcela de seu PIB com o turismo. De fato, se a economia de um determinado país é atingida, os outros também serão afetados. Grupos terroristas possuem grandes fontes de sustentação pois são reforçados por outros governos e outros grupos que tornam-se aliados, há então a criação de instrumentos de destruição em massa (ADM) e cada vez mais os investimentos são para a guerra. A nossa Constituição Federal proíbe a utilização da energia nuclear para fins não pacíficos (art. 21, XXIII, alínea a), sendo a normatização rigorosa ao tratar de métodos que possam afetar a vida de milhares, o que é realmente benéfico, mostrando que nosso país defende arduamente o direito à vida da população, o que não acontece em muitos países.

Art.21,[...] inciso XXIII - explorar os serviços e instalações nucleares de qualquer natureza e exercer monopólio estatal sobre a pesquisa, a lavra, o enriquecimento e reprocessamento, a industrialização e o comércio de minérios nucleares e seus derivados, atendidos os seguintes princípios e condições: a) toda atividade nuclear em território nacional somente será admitida para fins pacíficos e mediante aprovação do Congresso Nacional $[\ldots]$

Com a política neoliberal, a ideia de livre mercado, menores gastos com serviços públicos, terceirização; aumenta, de fato, somente a ideia de igualdade, pois os direitos fundamentais são ignorados e, enquanto isso, o mercado, o dinheiro e o capitalismo é posto acima de tudo e de todos. Para Focault, o neoliberalismo americano, na verdade, encontra-se em uma ideia de "militarização" (DANNER, 2011, p.22,).

Ao redor do mundo, existe a ideia de Guerra ao Terror, criada por uma política norteamericana após o ataque realizado pelo grupo Al-Qaeda liderado por Osama Bin Laden em 11 de setembro, sendo esta a justificativa utilizada pelos Estados Unidos. Em 7 de outubro de 2001, tropas anglo-americanas atacaram o Afeganistão, que era controlado pelo grupo islâmico Talebã. Fato é, com o ataque dos Estados Unidos, cresce o ódio daquele que foi atacado. Sendo assim, há o crescimento do terrorismo, existe uma política de guerra e medo, que acaba por interferir na vida de inocentes. [...] "A história nos ensina: o remédio pode ser pior que a enfermidade" (TODOROV, 2010, p. 15).

Com o uso e a ameaça de uso da violência; a consequência são as migrações e imigrações ilegais pelas populações que mais sofrem com os ataques. A pobreza e as respostas aos ataques influenciam nas decisões dessas pessoas; escolhendo elas a criminalidade.

O impacto causado por tais atentados e ameaças causa a desconfiança e medo aos consumidores e investidores, o que consequentemente impede a entrada de empreendedores aos 
países que sofrem com as ameaças desses grupos, impedindo o crescimento e desenvolvimento econômico dos países atacados, milhares perdem seus empregos, o que gera falência no mercado de trabalho e na criação de novas profissões.

\section{CONCLUSÃO}

Conforme o que foi exposto neste texto, o terrorismo consequentemente vem ganhando espaço, sendo um fator delimitador da democracia até então alcançada, causando uma regressão de direitos adquiridos em diversos países por ser realizado através da imposição, dominação e crueldade. No Brasil, a Constituição Federal de 1988 foi clara ao inseri-la no meio dos crimes hediondos e equiparados, com a lei antiterrorismo brasileira houve uma maior atenção ao fato e assim um meio de garantir a proteção do povo brasileiro e de todo nosso território.

Os avanços tecnológicos e a ciência são instrumentos positivos para o desenvolvimento da humanidade, porém, com o pós 11 de setembro todos esses meios vêm sendo utilizados para a produção de ADMs, mesmo com tratados e acordos realizados por países em conflitos ainda há investimentos cada vez maiores com armas e instrumentos de guerra.

A internet também vem sendo utilizada de forma errada, como conflitos entre internautas, de um lado a "esquerda" e de outro a "direita", havendo comentários com insultos cruéis e assustadores. Atualmente, a situação em que nós brasileiros estamos vivendo é de grande crise econômica, e assustador é ver os jovens, que serão responsáveis pelo futuro da nação brasileira pedindo pelo retorno da ditadura militar, bem como o movimento nazista ocorrido na Alemanha através das redes sociais, como Facebook, Blogs e Twitter.

Há grande necessidade de investimentos na educação, em todo o mundo, com uma educação de qualidade, continuaria a existir o terrorismo e a criminalidade, mas seria em menor quantidade, diminuindo cada vez mais e com ataques como o 11 de setembro, a população e os governantes deveriam buscar auxiliar para que isso não ocorresse novamente, não que os ataques aumentassem como vêm sendo. A sociedade atual vive pelo dinheiro, pelas marcas e pelos produtos. Uma boa qualidade de vida, uma boa educação, o interesse pelo bem, meio ambiente e própria humanidade estão sendo deixados de lado.

\section{REFERÊNCIAS BIBLIOGRÁFICAS}

BBC. Conheça seis fontes de renda do Estado Islâmico. Disponível em: http://www.bbc.com/portuguese/noticias/2015/11/151119_financiamento_estado_islamico_lgb. Acesso em: 24/06/2017

CALLEGARI, A. L.; Linhares, R. M. O combate ao terrorismo e a expansão do Direito Penal. Direito \& Justiça, Porto Alegre, v. 40, n. 2, p. 125-132, jul./dez, 2014.

DANNER, Fernando. Biopolítica e liberalismo: a crítica da racionalidade política em Michel Foucault. Porto Alegre, PUCRS, 2011.

PRADO, Luiz Regis. Curso de direito penal brasileiro, volume 1 : parte geral, arts. $1 .^{\circ}$ a 120 / Luiz Regis Prado. - 7. ed. rev., atual, e ampl. - São Paulo : Editora Revista dos Tribunais (p.140), 2007.

REDAÇÃO ÉPOCA. De onde vem o dinheiro do Estado Islâmico?. Disponível em: http://epoca.globo.com/tempo/filtro/noticia/2015/10/de-onde-vem-o-dinheiro-do-estadoislamico.html. Acesso em: 26/06/2017 
SOUZA, M. A; NASSER, M. R; MORAES, F. R. Do 11 se setembro de 2001 à guerra ao terror: reflexões sobre o terrorismo no século XX1. Brasília: Ipea, 2014.

TZVETAN, Todorov. O medo dos bárbaros: para além do choque das civilizações. Rio de Janeiro, Vozes, 2010.

VIGNA, Edélcio. Brasil maior exportador de riquezas naturais. Disponível em: http://www.inesc.org.br/noticias/noticias-do-inesc/2012/outubro/brasil-maior-exportador-deriquezas-naturais. Acesso em: 14/08/2017 